geget (2019) Volume 14 - Issue1

Original Article

\title{
Acute kidney Injury in Critically III Children; Frequency, Risk Factors and Outcomes.
}

\author{
Heba Mostafa Ahmed, Osama Ezzat Botrous, Eman Mohammed Ali \\ Department of Pediatrics, Faculty of Medicine, Beni- Suef University, Egypt.
}

\begin{abstract}
Introduction

Acute kidney injury (AKI) is a common problem in critically ill children and is associated with high rate of mortality. The definition and staging of AKI has been recently standardized using the RIFLE classification and the KDIGO classifications. Most cases of AKI represent acute tubular necrosis that is secondary to hypovolemia, sepsis or the use of nephrotoxic agents.
\end{abstract}

\section{Aim of the study}

To investigate the frequency, risk factors and outcome in critically ill children and to compare the pRIFLE and KDIGO classifications.

\section{Patients and methods}

100 critically ill children admitted to the pediatric intensive care unit (PICU) were screened for AKI using both pRIFLE and KDIGO classifications. All included children were subjected to full history taking, full clinical examination, assessment of disease severity at admission, daily monitoring of urine output serum creatinine and calculation of estimated GFR and inotrope score.

\section{Results}

Thirty -eight percent of our patients had developed AKI during their course of stay. There was no significant difference between the two scoring systems at admission at day 3and at day 7 post admission. Infant age group, duration of stay $>7$ days, the use of vasoactive drugs, nephrotoxic drugs and mechanical ventilation were risk factors for the development of AKI. Mortality was significantly higher in patients with AKI (58\% versus $13 \%, \mathrm{p}=.008)$.

\section{Conclusion}

Lower age, higher IS score and mechanical ventilation were independent risk factors for AKI. AKI was associated with higher mortality and was associated with significantly longer ICU stay.

\section{Key words}

Acute kidney injury; critically ill children; pRIFLE

\section{Correspondence}

Heba Mostafa Ahmed

Department of Pediatrics, Faculty of Medicine, Beni- Suef University, Egypt.

E-mail: heba_most@yahoo.com

\author{
geget : The Journal of the Egyptian Society of Pediatric Nephrology and Transplantation (ESPNT) \\ geget https://geget.journals.ekb.eg/ \\ Published by ESPNT http://espnt.net/ \\ Cohosted by Egyptian Knowledge Bank https://www.ekb.eg
}




\section{Introduction}

Acute kidney injury (AKI) (previously called acute renal failure) is characterized by a reversible impairment of renal functions and the inability of the kidney to regulate fluid and electrolyte homeostasis appropriately [1]. AKI is a common problem in children admitted to hospital, especially those necessitating intensive care unit admission, and it is an independent risk factor for increased mortality and severe morbidity [2] the Acute Dialysis Quality Initiative group created the RIFLE criteria in 2004, establishing a multidimensional, staged definition [3]. Since then, the RIFLE criteria have been modified three times. The first modification, the Pediatric RIFLE
(pRIFLE) criteria, modified the RIFLE criteria for use in children [4]. The second modified definition, the AKI Network (AKIN) criteria, expanded the diagnosis of AKI to include patients who experienced $\mathrm{a} \geq 0.3-\mathrm{mg} / \mathrm{dl}$ increase in serum creatinine in a 48-hour period [5].The most recent modification, the Kidney Disease Improving Global Outcomes (KDIGO) classification system, harmonized RIFLE, AKIN, and pRIFLE [6] (table 1). Most cases of incident AKI represent acute tubular necrosis (ATN) that is secondary to hypovolemia, sepsis or the use of nephrotoxic agents [7]. The aim of this study was to investigate the frequency, risk factors and outcome in critically ill children admitted to the PICU and to compare the pRIFLE and KDIGO classifications for staging of AKI.

Table 1: Different AKI staging systems

\begin{tabular}{|c|c|}
\hline Definition and Criteria for AKI Stages & Modifications \\
\hline pRIFLE & \\
\hline $\begin{array}{l}\text { Stage } 1 \text { (Risk): eGFR decreased by } 25 \% \\
\text { Stage } 2 \text { (Injury): eGFR decreased by } 50 \% \\
\text { Stage } 3 \text { (Failure): eGFR decrease by } 75 \% \\
\text { or } \\
\text { eGFR } \quad<35 \mathrm{ml} / \mathrm{min} \text { per } 1.73 \mathrm{~m}^{2}\end{array}$ & \\
\hline \multicolumn{2}{|l|}{ AKIN } \\
\hline $\begin{array}{l}\text { Stage 1: Increase in creatinine of } \geq 50 \% \\
\text { or } \\
\text { Absolute increase in creatinine of } 0.3 \mathrm{mg} / \mathrm{dl} \\
\text { Stage 2: Increase in creatinine of } \geq 100 \% \\
\text { Stage 3: Increase in creatinine of } \geq 200 \%\end{array}$ & $\begin{array}{l}0.3-\mathrm{mg} / \mathrm{dl} \text { increase added to stage } 1 \\
\text { AKI diagnosed over } 48 \text {-hr period }\end{array}$ \\
\hline \multicolumn{2}{|l|}{ KDIGO } \\
\hline $\begin{array}{l}\text { Stage 1: Increase in creatinine of } \geq 50 \% \\
\text { or } \\
\text { Absolute increase in creatinine of } 0.3 \mathrm{mg} / \mathrm{dl} \\
\text { Stage 2: Increase in creatinine of } \geq 100 \% \\
\text { Stage } 3 \text { : Increase in creatinine of } \geq 200 \% \\
\text { or } \\
\text { eGFR } \leq 35 \mathrm{ml} / \mathrm{min} \text { per } 1.73 \mathrm{~m}\end{array}$ & $\begin{array}{l}\text { eGFR threshold from } \mathrm{p} \text { RIFLE added to } \\
\text { stage } 3 \text { Creatinine changes } \\
\text { (except absolute } 0.3-\mathrm{mg} / \mathrm{dl} \text { increase) } \\
\text { required to occur within a } 7 \text {-d time frame }\end{array}$ \\
\hline
\end{tabular}

eGFR $=$ estimated glomerular filtration rate

\section{Methodology}

This observational study was conducted between December 2017 and November 2018. One-hundred patients aged 29days to 14 years screened for acute kidney injury (AKI) according to pRIFLE criteria and KDIGO classification. The severity of illness at admission was assessed by The Pediatric Risk of Mortality (PRISM III) scoring [8]. The exclusion criteria were: age less than 29 days or more than 14 years, duration of ICU admission less than 24 hours and patients known or proved to have an underlying renal disease (nephrotic syndrome, chronic kidney disease, renal tubular disorders or anatomical anomalies and obstructive uropathies..etc). All patients with AKI were classified based on pRIFLE criteria and KDIGO classification at admission and subsequently during their PICU stay. The maximal AKI score achieved was recorded. When baseline serum creatinine (Scr) was unknown in patients with no history of chronic kidney disease, baseline estimated creatinine clearance was calculated using Schwartz equation from SCr measured if available before this admission, or patients were assumed to have basal creatinine clearance $>100 \mathrm{~mL} / \mathrm{min} / 1.73 \mathrm{~m}^{2}$. All included children were subjected to full history taking, full clinical examination, daily monitoring of urine output serum creatinine and calculation of estimated GFR according to Schwartz formula [9]. Patients who received inotropes, their inotrope score (IS) was calculated according to the following formula ; Dopamine dose $(\mu \mathrm{g} / \mathrm{kg} / \mathrm{min})+$ dobutamine dose $(\mu \mathrm{g} / \mathrm{kg} / \mathrm{min})+100 \mathrm{x}$ epinephrine dose $(\mu \mathrm{g} / \mathrm{kg} / \mathrm{min})$ [10] and recalculate with each dose change then the maximum score was recorded. The followings were considered as potential risk factors for the development of acute renal injury: Respiratory failure, hypovolemic or hemorrhagic shock, cardiovascular disease, infections, trauma, surgery, presence of severe hypoxemia defined as $\mathrm{PaO} 2 / \mathrm{FiO} 2$ (partial pressure of arterial oxygen/fraction of inspired oxygen) less than 200 , mechanical ventilation and the use of nephrotoxic agents . According to the age, patients were divided into three age groups; infants $(<2$ years age $)$, preschool children $(2$ years $)$ and school children ( $>6$ years).

The duration of PICU stay was classified into $<7$ days and $>7$ days. 


\section{Statistical analysis}

Statistical analysis was done using statistical package for social sciences (SPSS), computer software (version22), IBM software, USA. Data were described in the form of median (IQR) for quantitative data, and frequency and proportions for qualitative data. A p value $<0.05$ was considered statistically significant. Differences were analyzed between the groups by Chi squared test and measurement of relative risk (RR); otherwise, MannWhitney U test was used. Associations were analyzed by logistic regression tests. Paired samples T test was used to compare the pRIFLE and KDIGO classifications.

\section{Results}

Out of 138 patients admitted to the PICU, 100 patients were included in the study. Thirty eight percent of our patients had developed AKI during their course of stay. The frequency of AKI stages according to both pRIFLE and KDIGO classifications at day 3 and day 7 of admission are shown in (figure 1). There was no significant difference between the two scoring systems at admission, at day 3 and at as regarding frequency of AKI ( $p=0.31$ and $42,0.42$ respectively) or clinical data (table 2 ). At day three, $26 \%$ of the patients developed AKI (6\% R "stage 1", $12 \%$ I" stage 2 "and $8 \% \mathrm{~F}$ "stage 3"). At day 7, 37\% had AKI (15\% R "stage 1", $8 \%$ I "stage 2"and 14\% F "stage 3"). At the final outcome (discharge or death), $21 \%$ had AKI (5\% stage 1 "R", $2 \%$ stage 2 "I" and $14 \%$ stage 3" F"). $32 \%$ of AKI patients by either classifications developed oliguria or anuria and 4 patients underwent peritoneal dialysis. On comparing patients with and without AKI; infant age group, duration of stay $>7$ days, the use of vasoactive drugs, nephrotoxic drugs and mechanical ventilation were statistically significant risk factors for the development of AKI. As regarding patients outcome, mortality was significantly higher in patients with AKI (58\% versus $13 \%, \mathrm{p}=0.008)$, (table 3$).$ On comparing different stages of AKI; the frequency day 7 post admission of duration of stay $>7$ days, inotropes use, mechanical ventilation and mortally were significantly higher among patients with stage 3 (F stage) (table 4). The PRISM score was statistically insignificant between patients with and without AKI while the inotrope score was significantly higher in patients with AKI. Both PRISM and IS score were significantly higher in patients who had poor outcome and mortality (table 5). Prolonged duration of stay and mechanical ventilation and AKI stage 3 (F) were independent risk factors for mortality in our patients (table 6).

Table 2: Comparison between pRIFLE and KDIGO classifications as regarding different clinical data.

\begin{tabular}{|c|c|c|c|c|}
\hline & & $\begin{array}{c}\text { pRIFLE } \\
(\mathrm{n}=31)\end{array}$ & $\begin{array}{c}\text { KDIGO } \\
(\mathrm{n}=\mathbf{3 4})\end{array}$ & $\mathbf{p}$ \\
\hline \multirow{2}{*}{ Sex } & Male & $21 \quad(67 \%)$ & $20(59 \%)$ & \multirow{2}{*}{$>.05$} \\
\hline & Female & 10 & 14 & \\
\hline \multirow{3}{*}{ Age } & Infants & $22(71 \%)$ & $24(70 \%)$ & \multirow{3}{*}{$>.05$} \\
\hline & Preschool & $5(16 \%)$ & $6(18 \%)$ & \\
\hline & School & $4(13 \%)$ & $4(12 \%)$ & \\
\hline \multirow{2}{*}{ Duration of stay } & $<7$ days & $7(22 \%)$ & $5(15 \%)$ & \multirow{2}{*}{$>.05$} \\
\hline & $>$ 7days & $24(88 \%)$ & $29(85 \%)$ & \\
\hline Sepsis & & $21(68 \%)$ & $23(68 \%)$ & $>.05$ \\
\hline $\begin{array}{c}\text { Respiratory } \\
\text { failure }\end{array}$ & & $3(10 \%)$ & $4(12 \%)$ & $>.05$ \\
\hline Surgical & & $8(26 \%)$ & $9(26 \%)$ & $>.05$ \\
\hline Nephrotoxic drugs & & $29(94 \%)$ & $32(94 \%)$ & $>.05$ \\
\hline Vasoactive drugs & & $20(65 \%)$ & $24(71 \%)$ & $>.05$ \\
\hline $\begin{array}{c}\text { Mechanical } \\
\text { ventilation }\end{array}$ & & $19(61 \%)$ & $22(65 \%)$ & $>.05$ \\
\hline \multirow{2}{*}{ Out come } & Discharge & $9(29 \%)$ & $12(35 \%)$ & \multirow{2}{*}{$>.05$} \\
\hline & Death & $22(71 \%)$ & $22(65 \%)$ & \\
\hline
\end{tabular}





Figure 1: Comparison between pRIFLE and KDIGO staging systems at different duration. 
Table 3: Relative risk for development of AKI in study patients according to demographic \& clinical data.

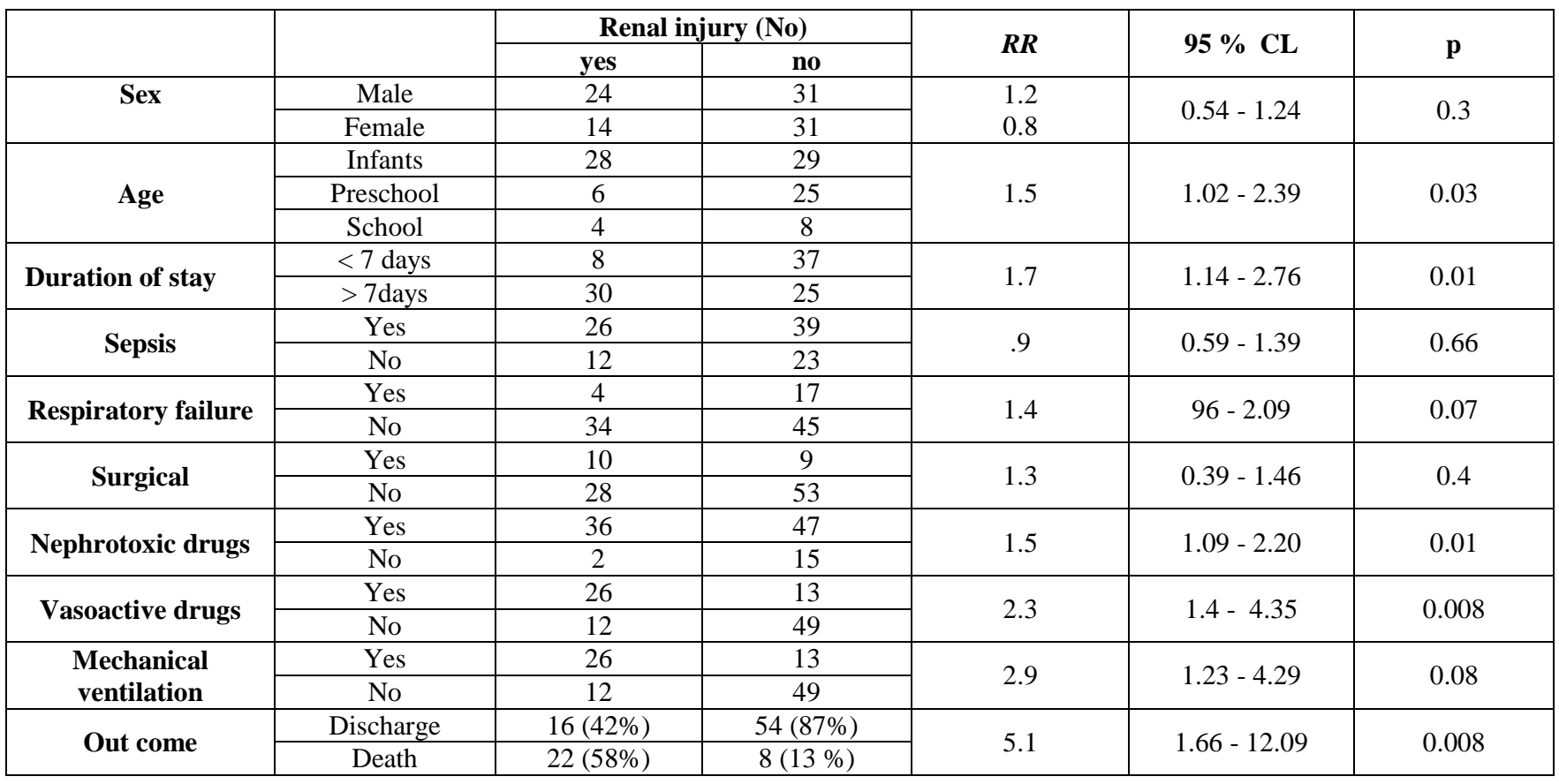

Table 4: Risk factors in different AKI stages (no. of patients).

\begin{tabular}{|c|c|c|c|c|c|c|}
\hline & & $\mathbf{R}$ (stage 1) & I (stage 2) & F (stage 3) & $X^{2}$ & $p$ \\
\hline \multirow{2}{*}{ Age } & $<2$ years & 10 & 8 & 10 & \multirow{2}{*}{10.2} & \multirow{2}{*}{0.33} \\
\hline & $>2$ years & 6 & 0 & 4 & & \\
\hline \multirow{2}{*}{ Duration of stay } & $<7$ days & 6 & 2 & 0 & \multirow{2}{*}{9.3} & \multirow{2}{*}{0.03} \\
\hline & $>7$ days & 10 & 6 & 14 & & \\
\hline \multirow{2}{*}{ Sepsis } & Yes & 4 & 2 & 6 & \multirow{2}{*}{.8} & \multirow{2}{*}{0.8} \\
\hline & No & 12 & 6 & 8 & & \\
\hline \multirow{2}{*}{ Nephrotoxic drugs } & Yes & 14 & 8 & 14 & \multirow{2}{*}{5.9} & \multirow{2}{*}{0.2} \\
\hline & $\mathrm{No}$ & 2 & 0 & 0 & & \\
\hline \multirow{2}{*}{ Inotropes } & Yes & 10 & 6 & 14 & \multirow{2}{*}{16} & \multirow{2}{*}{$<.001$} \\
\hline & No & 6 & 3 & 0 & & \\
\hline \multirow{2}{*}{$\begin{array}{l}\text { Mechanical } \\
\text { ventilation }\end{array}$} & Yes & 10 & 2 & 14 & \multirow{2}{*}{17.4} & \multirow{2}{*}{$<.001$} \\
\hline & No & 6 & 6 & 0 & & \\
\hline \multirow{2}{*}{ Fate } & Discharge & 14 & 2 & 0 & \multirow{2}{*}{26.3} & \multirow{2}{*}{$<.001$} \\
\hline & Death & $2(12.5 \%)$ & $6(75 \%)$ & $14(100 \%)$ & & \\
\hline
\end{tabular}

Table 5: PRISM and IS as risk factors for AKI and mortality.

\begin{tabular}{|c|c|c|c|c|c|}
\hline & & PRISM & p & IS & P \\
\hline \multirow{2}{*}{ AKI } & Yes & $13(5-37)$ & 0.09 & $16(0-37)$ & $0(0-10)$ \\
\hline \multirow{2}{*}{ Outcome } & No & $7.3(3-28)$ & 0.007 \\
& Good & $9(3-28)$ & $<0.001$ & $25(16-37)$ & $<0.001$ \\
\hline
\end{tabular}


Table 6: Assessment of risk factors fort mortality using logistic regression.

\begin{tabular}{|c|c|c|c|c|c|c|}
\hline & B & \multirow{2}{*}{ Std. Error } & \multirow{2}{*}{ Sig. } & \multirow{2}{*}{$\operatorname{Exp(B)}$} & \multicolumn{2}{|c|}{ 95\% Confidence Interval for Exp(B) } \\
\cline { 5 - 7 } & & & & \multicolumn{2}{|c|}{ Lower Bound } & Upper Bound \\
\hline Duration of stay & 2.182 & 0.691 & 0.047 & 3.261 & 0.841 & 12.646 \\
\hline AKI & 0.332 & 0.667 & 0.618 & 1.394 & 0.377 & 5.156 \\
\hline AKI stage 1 (R) & 0.262 & 1.47 & 0.858 & 1.300 & 0.072 & 23.43 \\
\hline AKI stage 2 ( I ) & 1.87 & 1.25 & 0.136 & 6.512 & 0.554 & 76.178 \\
\hline AKI stage 3 ( F) & 3.258 & 1.173 & 0.005 & 62.13 & 2.607 & 259.3 \\
\hline SEPSIS & 0.106 & 0.686 & .878 & 1.111 & 0.290 & 4.267 \\
\hline Mechanical ventilation & 2.351 & 1.286 & .048 & 1.095 & 0.08 & 1.185 \\
\hline
\end{tabular}

\section{Discussion}

Thirty- eight out of 100 patients admitted to the PICU and met the inclusion criteria developed AKI, an incidence of $38 \%$. Many Studies of AKI in the PICU had stated an AKI incidence ranging widely from $4.5-70 \%$.[11,12] In the study by Mehta et al.,[13] they reported a $36.1 \%$ incidence of AKI while Naik et al,[14] reported an incidence of $40.9 \%$ which are similar to ours. Different definitions of AKI may account for the reported differences in the incidence of AKI. Zappitelli [15] showed that more patients were diagnosed as having AKI using baseline estimated creatinine clearance compared to using change in creatinine as the defining criteria for diagnosis of AKI. They also showed that assuming a baseline eCCL of 120 $\mathrm{ml} / \mathrm{min}$ was also associated with higher incidence of AKI compared to assuming $100 \mathrm{ml} / \mathrm{min}$ as baseline eCCL. To define AKI we used both pRIFLE and KDIGO classifications and compared them without a significant difference between the two classifications as we assumed $100 \mathrm{ml} / \mathrm{min} / 1.73 \mathrm{~m}^{2}$ as baseline eCCL and we also used the urine output criteria which is almost similar in the two classifications. In our study, $37 \%$ patients had AKI at admission while nearly $68 \%$ developed AKI within 72 hours, similar to the study by Schneider et al., who reported that almost $50 \%$ patients developed their maximum RIFLE score within $48 \mathrm{~h}$ of ICU admission and about $75 \%$ achieved it by the 7th day of PICU stay [15].

We found that lower age, higher duration of stay, higher IS score, mechanical ventilation and the use of nephrotoxic drugs were risk factors for development of AKI. Various studies have attempted to identify risk factors for development of AKI in critically ill children [11, 12]. Mehta et al. [13] found that younger age, shock, sepsis and need for mechanical ventilation were independent risk factors for AKI, similar finding were reported by Maqpool et al [11]. In our study sepsis was not a risk factor for AKI a finding that can be explained by that our patients are exposed to other risk factors specially nephrotoxic drugs even in non-AKI group masking the effect of sepsis. Patients with AKI had significantly longer PICU stay and higher mortality rate compared to patients without AKI. In concurrence with our finding, several studies have shown that AKI is associated with a significant increase in mortality [4, 12, and 16 ]. Similarly, Severe AKI (AKI stage 3 or F) was found to be an independent predictor of mortality in our study. In contrast to our findings, Mehta et al. [13] found that although mortality was higher in patients with AKI than those without AKI (37\% vs. 8.7\%), AKI was not an independent risk of mortality. We also found that though there was a significant trend of higher mortality with higher AKI stage, AKI as a whole was not an independent predictor of mortality. Need for mechanical ventilation, longer duration of stay and severe AKI were the independent risk factors of mortality in our study. This suggests that increased mortality seen in patients with AKI is largely because patients with AKI are sicker with more increased need for mechanical ventilation and longer duration of admission.

\section{Limitations of the study}

Relatively small number of patients being a single center experience so larger population studies are required to verify our findings

\section{Conclusion}

AKI is common in critically ill children. Lower age, higher IS score and mechanical ventilation were independent risk factors for AKI. AKI was associated with higher mortality and was associated with significantly longer ICU and hospital stay.

\section{References}

1. Andreoli SP. Acute renal failure. Curr Opin Pediatr. 2002; 14:183-188

2. Alkandari O, Eddington KA, Hyder A, Gauvin F, Ducruet T, Gottesman R, Phan V, Zappitelli M..Acute kidney injury is an independent risk factor for pediatric intensive care unit mortality, longer length of stay and prolonged mechanical ventilation in critically ill children: a two-center retrospective cohort study.

Crit Care. 2011, Jun 10; 15(3):R146. 
3. Bellomo R, Ronco C, Kellum JA, Mehta RL, Palevs kyP, Acute Dialysis Quality Initiative workgroup: Acute renal failure - definition, outcome measures, animal models, fluid therapy and information technology needs: The Second International Consensus Conference of the Acute Dialysis Quality Initiative (ADQI) Group.

Crit Care... 2004, 8: R204-R212.

4. Akcan-Arikan A, Zappitelli M, Loftis LL, Washburn KK, Jefferson LS, Goldstein SL. Modified RIFLE criteria in critically ill children with acute kidney injury.

Kidney Int.; 2007, 71: 1028-1035.

5. Mehta RL, Kellum JA, Shah SV, Molitoris BA, Ronco C, Warnock DG, Levin A. Acute Kidney Injury N, and Acute Kidney Injury Network: Acute Kidney Injury Network: Report of an initiative to improve outcomes in acute kidney injury. Crit Care; 2007, 11: R31.

6. KDIGO AKI Work Group: KDIGO clinical practice guideline for acute kidney injury.

Kidney Int Suppl.; 2012, 2: 1-138.

7. Basu RK, Prasad DP, Wong H, Wheeler DS. An update and review of acute kidney injury in pediatrics. Pediatr Crit Care Med.; .2011, 12:339-47.

8. Pollack .M. M., Patel K. M., Ruttimann U. E. PRISM III: an updated Pediatric Risk of Mortality score Crit Care Med. May; 1996, 24(5): 743-752.

9. Schwartz GJ, Haycock GB, Edelmann CM Jr, Spitzer A. A simple estimate of glomerular filtration rate in children derived from body length and plasma creatinine. Pediatrics. 1976, 58: 259-263.
10. Gaies MG, Gurney JG, Yen AH, Napoli ML, Gajarski RJ, Ohye RG, Charpie JR, Hirsch JC. Vasoactive-Inotropic Score as a predictor of morbidity and mortality in infants after cardiopulmonary bypass. Pediatr Crit Care Med; 2010, 11:234-238.

11. Maqbool J, Mir AA, Bhat NA, Moona WQ. Incidence and etiology of acute kidney injury in children admitted to PICU using pRIFLE criteria. Maqbool J et al. Int J Contemp Pediatr. May; 2018,5(3):917-921.

12. Kaddourah A, Basu AU, Rajit K. Bagshaw SM,,Stuart L. Goldstein SL; Epidemiology of Acute Kidney Injury in Critically Ill Children and Young Adults. N Engl J Med; 2017, 376: 11-20.

13. Mehta P, Sinha A, Sami A. Incidence of acute kidney injury in hospitalized children.

Indian Pediatr. ; 2012, 9:537-42.

14. Naik S, Sharma J, Yengkom R, Kalrao V, Mulay A, 2014. Acute kidney injury in critically ill children: Risk factors and outcomes.

Indian J Crit Care Med.; 2014, 18(3):129-33.

15. Zappitelli M, Parikh CR, Akcan-Arikan A, Washburn KK, Moffett BS, Goldstein SL. Ascertainment and epidemiology of acute kidney injury varies with definition interpretation.

Clin J Am Soc Nephrol ; 2008, 3:948-54.

16. Park WY, Hwang EA, Jang MH, Park SB, Kim HC. The risk factors and outcome of acute kidney injury in the intensive care units.

Korean J Intern Med.; 2010, 25: 181-7.

\section{Declaration}

\section{Ethics approval and consent to participate}

This study protocol and the consents were approved and deemed sufficient by Ethical Committee of Pediatric Department, Faculty of Medicine, Beni- Suef University. And informed written consent was obtained in every case from their legal guardians. Funding

The authors declare that they didn't receive any financial support from agencies or others.

Conflict of interest

No

Acknowledgements

We would like to thank all patients and their family members for their valuable contributions to the study. 